\title{
Use of Transition Modeling to Enable the Computation of Losses for Variable-Speed Power Turbine
}

Ali A. Ameri

Ohio State University, Columbus, Ohio 


\section{NASA STI Program . . . in Profile}

Since its founding, NASA has been dedicated to the advancement of aeronautics and space science. The NASA Scientific and Technical Information (STI) program plays a key part in helping NASA maintain this important role.

The NASA STI Program operates under the auspices of the Agency Chief Information Officer. It collects, organizes, provides for archiving, and disseminates NASA's STI. The NASA STI program provides access to the NASA Aeronautics and Space Database and its public interface, the NASA Technical Reports Server, thus providing one of the largest collections of aeronautical and space science STI in the world. Results are published in both non-NASA channels and by NASA in the NASA STI Report Series, which includes the following report types:

- TECHNICAL PUBLICATION. Reports of completed research or a major significant phase of research that present the results of NASA programs and include extensive data or theoretical analysis. Includes compilations of significant scientific and technical data and information deemed to be of continuing reference value. NASA counterpart of peer-reviewed formal professional papers but has less stringent limitations on manuscript length and extent of graphic presentations.

- TECHNICAL MEMORANDUM. Scientific and technical findings that are preliminary or of specialized interest, e.g., quick release reports, working papers, and bibliographies that contain minimal annotation. Does not contain extensive analysis.

- CONTRACTOR REPORT. Scientific and technical findings by NASA-sponsored contractors and grantees.
- CONFERENCE PUBLICATION. Collected papers from scientific and technical conferences, symposia, seminars, or other meetings sponsored or cosponsored by NASA.

- SPECIAL PUBLICATION. Scientific, technical, or historical information from NASA programs, projects, and missions, often concerned with subjects having substantial public interest.

- TECHNICAL TRANSLATION. Englishlanguage translations of foreign scientific and technical material pertinent to NASA's mission.

Specialized services also include creating custom thesauri, building customized databases, organizing and publishing research results.

For more information about the NASA STI program, see the following:

- Access the NASA STI program home page at http://www.sti.nasa.gov

- E-mail your question via the Internet to help@ sti.nasa.gov

- Fax your question to the NASA STI Help Desk at $443-757-5803$

- Telephone the NASA STI Help Desk at 443-757-5802

- Write to: NASA Center for AeroSpace Information (CASI) 7115 Standard Drive Hanover, MD 21076-1320 


\section{Use of Transition Modeling to Enable the Computation of Losses for Variable-Speed Power Turbine}

Ali A. Ameri

Ohio State University, Columbus, Ohio

Prepared for the

TURBO EXPO 2012

sponsored by the American Society of Mechanical Engineers (ASME)

Copenhagen, Denmark, June 11-15, 2012

Prepared under Contract NNC06BA07B, Task NNC10E420T-0

National Aeronautics and

Space Administration

Glenn Research Center

Cleveland, Ohio 44135 


\section{Acknowledgments}

This work was sponsored by the NASA Fundamental Aeronautics Program, Subsonic Rotary Wing Project The author wishes to express his gratitude to Dr. Gerard Welch of NASA Glenn Research Center for his guidance and review of this work. I acknowledge Dr. Paul Giel's sharing of data and his careful review of the manuscript and the many useful corrections and suggestions. Thanks are also due to my colleague Dr. David Rigby for his review and Dr. James Heidmann chief of the Turbomachinery and Heat Transfer Branch of NASA Glenn Research Center for his support.

This report contains preliminary findings, subject to revision as analysis proceeds.

This report is a preprint of a paper intended for presentation at a conference.

Because changes may be made before formal publication, this preprint is made available

with the understanding that it will not be cited or reproduced without the permission of the author.

Trade names and trademarks are used in this report for identification only. Their usage does not constitute an official endorsement, either expressed or implied, by the National Aeronautics and Space Administration.

This work was sponsored by the Fundamental Aeronautics Program at the NASA Glenn Research Center.

Level of Review: This material has been technically reviewed by NASA technical management.

Available from

NASA Center for Aerospace Information 7115 Standard Drive Hanover, MD 21076-1320
National Technical Information Service 5301 Shawnee Road Alexandria, VA 22312 


\title{
Use of Transition Modeling to Enable the Computation of Losses for Variable-Speed Power Turbine
}

\author{
Ali A. Ameri \\ Ohio State University \\ Columbus, Ohio 43235
}

\begin{abstract}
To investigate the penalties associated with using a variable speed power turbine (VSPT) in a rotorcraft capable of vertical takeoff and landing, various analysis tools are required. Such analysis tools must be able to model the flow accurately within the operating envelope of VSPT. For power turbines low Reynolds numbers and a wide range of the incidence angles, positive and negative, due to the variation in the shaft speed at relatively fixed corrected flows, characterize this envelope. The flow in the turbine passage is expected to be transitional and separated at high incidence. The turbulence model of Walters and Leylek was implemented in the NASA Glenn-HT code to enable a more accurate analysis of such flows. Two-dimensional heat transfer predictions of flat plate flow and two-dimensional and threedimensional heat transfer predictions on a turbine blade were performed and reported herein. Heat transfer computations were performed because it is a good marker for transition. The final goal is to be able to compute the aerodynamic losses. Armed with the new transition model, total pressure losses for three-dimensional flow of an Energy Efficient Engine $\left(E^{3}\right)$ tip section cascade for a range of incidence angles were computed in anticipation of the experimental data. The results obtained form a loss bucket for the chosen blade.
\end{abstract}

\section{Nomenclature}

$C_{p} \quad$ loss coefficient

$C_{f} \quad$ friction coefficient

$C_{x} \quad$ axial chord

$h \quad$ heat transfer coefficient

$k \quad$ turbulence kinetic energy

M Mach number

$\mathrm{Nu} \quad$ Nusselt number

$P \quad$ pressure

Pr Prandtl number

$q \quad$ wall heat flux

$r$ recovery factor

$\mathrm{Re} \quad$ Reynolds number defined based on axial momentum or exit isentropic conditions

St $\quad$ Stanton number $=\mathrm{Nu} /(\operatorname{Re} * \operatorname{Pr})$

$T \quad$ static temperature

$u \quad$ flow velocity

$x$ axial distance

$y \quad$ pitchwise coordinate

$Z \quad$ spanwise direction

Subscripts:

0 total condition

2 exit isentropic conditions

aw adiabatic wall value

in inlet condition 
l laminar condition

$T$ turbulent condition

$s \quad$ static isentropic condition

$t$ total value

w wall value

$\mathrm{x} \quad$ local value

$\infty \quad$ free stream condition

Greek:

$\gamma \quad$ specific heat ratio

$\delta \quad$ inlet boundary layer thickness

$\omega \quad$ specific turbulent dissipation

\section{Introduction}

A key goal of the Subsonic Rotary Wing project is to enhance utilization of civil rotorcraft to relieve airport congestion and increase throughput capacity. One concept that has been advocated for this purpose is the use of tilt rotor aircraft to enable vertical takeoff and landing. In order to bring about fuel efficiency the main-rotor speed needs to vary from 100 percent at takeoff to 50 percent at cruise. This can be achieved by using a two-speed transmission driven by a power turbine with minimal speed change. To avoid the added weight and complexity of a two-speed transmission a variable speed power turbine (VSPT) can be used with a of fixed gear ratio transmission. To investigate the penalties associated with this alternative, various analysis tools are required. Such analysis tools must be able to model the flow accurately within the operating envelope. For power turbines this envelope is characterized by low Reynolds numbers and a wide range of incidence angles, both positive and negative, due to the variation in the shaft speed at relatively fixed corrected flows. Lessons from the operation of Low Pressure Turbines and studies carried out for Low Pressure Turbines may be a source for guidance.

Low Pressure Turbines have been reported to suffer loss of efficiency at higher altitudes under cruise conditions (Refs. 1, 2, and 3). At the cruise condition, Reynolds number is at its lowest in the flight envelope. Such low Reynolds number conditions allow existence of laminar boundary layers. Laminar boundary layers propensity for rapid thickening lead to more dominant secondary flows. This also can lead to flow separation on the suction side of the blades if the boundary layer does not transition. The separated boundary layer, if not reattached, gives rise to large losses and deviations. For the VSPT, in addition to the low Reynolds number condition, changes in incidence, whether positive or negative, produce different physical effects. Positive incidence increases blade loading and enlargements of the vortical structures while it can enhance flow separation on the suction side. Negative incidence unloads the blade and may give rise to pressure side cove separation (Ref. 4). Identified by Welch (Ref. 4), low Reynolds number effects on losses in Variable Power Speed Turbine is an area for which our understanding needs to be improved.

Accurate prediction of losses under the conditions noted above is a challenge for CFD. The state of the boundary layer (laminar, transitional or turbulent) has a large effect on the aerodynamic losses and thus a realistic prediction of the flow depends on its accurate modeling. In recent years, advances in transition modeling have been reported which are used in the present work.

\section{Objectives of This Work}

The objective of this work is to improve the predictive capability of CFD codes for flows relevant to variable speed power turbines, including the effects of low Reynolds numbers, large incidence variations, and flow separations. To this end, a new transition model was implemented into a three-dimensional steady RANS solver and assessed. This paper presents two-dimensional flat plate calculations as well as two-dimensional and three-dimensional heat transfer computations on a blade in a linear cascade with 
comparison to experimental data of Giel et al. (Ref. 4). Computations are for two distinct Reynolds numbers and show sensitivity to grid density and to variables such as turbulent length scale and inlet boundary layer thickness. The purpose is to help establish the ability of the transition model to predict the effects of transition in three-dimensional turbine blade passage flows. Subsequent to establishing satisfaction with the performance of the model as it pertains to transition, the paper presents losses computed for a different blade, an Energy Efficient Engine $\left(E^{3}\right)$ (Ref. 5) tip profile at zero tip clearance in a linear cascade with varying inlet incidence angle. In anticipation of experimental results from the NASA Glenn's Transonic Turbine Blade Cascade, the paper presents predicted wake loss profiles and finally the "loss bucket" for a single Reynolds number at various points on the incidence axis.

\section{Transition Modeling Options}

As a first task, a suitable turbulence model had to be chosen. Implementation of transition models in NASA codes is not a new endeavor. Various efforts have been undertaken to improve modeling of transition for turbomachinery (Refs. 7 to 10). For example, Ameri and Arnone (Ref. 10) undertook this task by implementing the intermittency models suggested by Mayle (Ref. 11) in a three-dimensional code and presented blade and endwall heat transfer comparisons to available experimental linear cascade data. In that work, transition was modeled by using algebraic transition criteria based on momentum Reynolds number and free stream turbulence correlations. Such a transition model would be sensitive to the state of the boundary layer and would "sense" the start and extent of transition based on experimental correlations derived from experiments. The progress of transition would be marked by an intermittency factor, which is zero for a laminar flow and unity for a fully turbulent flow. The modeling worked rather well but its use was limited by the necessity of computing integral velocity profile parameters such as momentum thickness. These parameters are not readily computable for three-dimensional flows involving endwalls, and in codes that use general multi-block grids or unstructured grids. This method of modeling was therefore excluded from the options considered.

Different dimensionless variables which are purported to describe the state of the flow and turbulence have been used in the context of two equation models to coax the models into "sensing" and producing transition. Savil (Ref. 12) has reported on a series of test cases performed with two-equation models and more elaborate non-linear Reynolds Stress and Reynolds Stress Transport models. The test cases are rather simple and the results are varied. It is doubtful that such models would be able to consistently predict flow transition in threedimensional flows. Another type of modeling option that has been exercised in two-dimensional flows involves using intermittency models for transition in the context of two-equation turbulence models. A combination of transport equations and algebraic correlations are used to describe the transition process (Refs. 13 and 14). To overcome the problem with transition modeling which uses boundary layer integral quantities researchers have taken up the approach to use a surrogate variable, which is described using a transport equation. This would obviate the need for direct computation of momentum thickness or complicating boundary layer quantities. Examples of such models which include the model of Menter et al. (Ref. 15) and the related model of Suluksna et al. (Ref. 16).

Another option available, and adopted here, is to use transport equations for transition and turbulence which use phenomenological models, as opposed to an empirically based models (Refs. 17 and 18), without the necessity to compute any boundary layer or integral quantities. In the work presented by Walters and Leylek (Ref. 18), a modified form of the $k-\omega$ model supplemented with a transport equation for the "laminar kinetic energy," forms a three-equation model. A study conducted by Cutrone (Ref. 19) et al. consisting of several models, including some of the models discussed above, showed this approach to be promising. A three-dimensional test for flow through a turbine cascade showed good agreement with experiments and superior to other models attempted. Other works using similar types of models such as the work of Pacciani et al. (Ref. 20), with separated flow through high-lift, low-pressure turbine blades, showed good agreement with experimental loss data.

In our work, early two-dimensional computations with this model on a turbine blade showed excellent agreement with heat transfer data which led to further testing of the model for three-dimensional flows. 


\section{Walters and Leylek Model}

The model of Walters and Leylek (Refs. 17 and 18) has been developed with the process of transition built-in from the start. Walters and Leylek report that in developing the model their intention was for the model to be "hands off" for the user requiring no modification with different application cases. It is a phenomenological model as opposed to an empirically based model. It is a "single point" model and does not require non-local or integral quantities.

\section{Modeling Background}

Low turbulence intensity in the free stream leads to natural transition of the boundary layer. With as low as one percent in intensity in free-stream turbulence, laminar velocity profile on the wall starts being affected by shifting momentum from outer region to inner region near the wall. Early attempts to model this effect relied upon turbulence diffusion and interaction with shear to promote transition. Experimental and computational evidence (Ref. 21) suggest that for the bypass transition the process of diffusion and interaction with shear may not be the governing mechanism. Large amplitude and low frequency streamwise fluctuations lead to increase in friction and wall heat transfer resulting in bypass transition as these streamwise fluctuations grow and breakdown. The low frequency aspect is critical. Shown by Moss and Oldfield (Ref. 22), the wall heat transfer does not respond to high frequency spectra in the free stream whereas the low frequency oscillations produces an increase in the level of wall heat transfer. Called "Splat Mechanism," and described by Bradshaw (Ref. 23), Volino and Simon (Ref. 24), by measuring the spectra of fluctuations in the free stream and in the boundary layer, showed that $-u^{\prime} v^{\prime}$ in the boundary layer upstream (in the pre-transitional region) occurs at the same frequency as $v^{\prime}$ in the upstream and thus is responsible for these oscillations. Boundary layer is selective to certain free stream eddy scales and low-frequency disturbances in the boundary layer are amplified by the mean shear. The dynamics embodied in these streamwise fluctuations, in the model of Walters and Leylek, is captured by a "Laminar Kinetic Energy" equation through a modification of the concept devised by Mayle and Schulz (Ref. 25). Splats occur only for eddies with large length scales relative to the wall distance. Walters and Leylek have distinguished a "wall limited" large scale and "non-wall limited," or small scale eddies in the near wall region. The effective eddy size delineates between larger eddies that contribute to the laminar kinetic energy $\left(k_{L}\right)$ and smaller ones that contribute to the turbulence. Transfer of energy from the Laminar Kinetic Energy to the turbulent fluctuations initiates transition once a threshold is reached. Additional measures are implemented in the model to allow for natural and mixed mode transition. The turbulence model, as originally conceived in Reference 17, consisted of transport equations for Laminar and turbulent kinetic energy, and rate of dissipation of kinetic energy of turbulence $\left(k_{L}, k_{T}\right.$, and $\left.\varepsilon\right)$. In a later paper (Ref. 18), the transport equations solved were modified to include $\omega$, the inverse turbulent time scale in place of $\varepsilon$. It is suggested in Reference 18 that the latter form leads to a better representation of the breakdown of laminar kinetic energy to turbulence. This form of model equations, but in compressible form, was implemented in the Glenn-HT code. The form is given below:

$$
\begin{aligned}
& \frac{\partial\left(\rho k_{l}\right)}{\partial t}+\frac{\partial}{\partial x_{j}}\left(\rho k_{l} u_{j}\right)=\frac{\partial}{\partial x_{j}}\left(\mu \frac{\partial k_{l}}{\partial x_{j}}\right)+P_{k l}-R_{B P}-R_{N A T}-D_{L} \\
& \frac{\partial\left(\rho k_{T}\right)}{\partial t}+\frac{\partial}{\partial x_{j}}\left(\rho k_{T} u_{j}\right)=\frac{\partial}{\partial x_{j}}\left(\mu+\frac{\rho \alpha_{T}}{\sigma_{K}} \frac{\partial k_{T}}{\partial x_{j}}\right)+P_{k T}+R_{B P}+R_{N A T}-D_{T} \\
& \frac{\partial(\rho \omega)}{\partial t}+\frac{\partial}{\partial x_{j}}\left(\rho \omega u_{j}\right)=\frac{\partial}{\partial x_{j}}\left(\mu+\frac{\rho \alpha_{T}}{\sigma_{\omega}} \frac{\partial \omega}{\partial x_{j}}\right)+P_{\omega}+C_{\omega R} \frac{\omega}{k_{T}}\left(R_{B P}+R_{N A T}\right) \\
& -C_{\omega 2} \rho \omega^{2}+S
\end{aligned}
$$


$P_{k l}$ and $P_{k T}$ are production terms for laminar and kinetic energy and consist of interaction of pretransitional and turbulent Reynolds stresses with mean shear. Terms such as $R_{B P}$ and $R_{N A T}$ appear with opposite sign in the two equations for the laminar and turbulent kinetic energy equations and their role is to transfer the parts of laminar kinetic energy related to natural and bypass transition to turbulent kinetic energy. The complete form and details may be found in Reference 18.

\section{Results}

\section{Heat Transfer Cases}

In this section, we first describe the data chosen for testing of the model. We next describe the physical modeling and the results of the testing.

\section{GE2 Blade}

Detailed heat transfer data are required to allow verification of transition modeling capability. Transition is strongly marked by the rate of heat transfer on blades. Thus, blade heat transfer data can be used for transition modeling validation purposes. The data used for this part of our work are from the experiment reported by Giel et al. (Ref. 5). The data were obtained for an industry-provided blade profile designated here as GE2. Blade GE2 is an extruded two-dimensional section of a first stage turbine blade for a GE heavy frame power turbine $\left(2500^{\circ} \mathrm{F}\right.$ class). Blade loading and nearly full-span heat transfer coefficient (Nusselt number) data were obtained by Giel et al. (Ref. 5) for a linear cascade of blades of this profile. Data were also obtained at 50, 25, and 15 percent of the design value of Reynolds number. The 15 and 25 percent design Reynolds numbers of 375,000 and 621,000 $\left(\operatorname{Re}_{2}\right)$ are used in this report. The design pressure ratio for the cases used was 1.44 and the design inlet angle was 59.1.

Table 1 lists the blade dimensions and other pertinent data. Inlet turbulence associated with the turbulence grid listed in Table 1 was measured to be 13 percent. A uniform heat flux was achieved on the blade surface by using a thin-film electrical heater. A liquid crystal method was used to measure the local wall temperature. For the computations, a uniform wall temperature of 1.2 times the inlet total temperature was specified. Giel et al. (Ref. 5) presented measurements for heat transfer over the whole of the blade. Mid-span data for GE2 were used for two-dimensional comparisons. Data at 15 and 25 percent span are also available and are used for three-dimensional comparisons. For the three-dimensional runs, in addition, an inlet endwall boundary layer thickness of 37 percent of the half-span, as measured experimentally, was specified at the inlet of the domain one axial chord upstream corresponding to the measuring station.

TABLE 1.-GEOMETRIC DATA FOR GE2

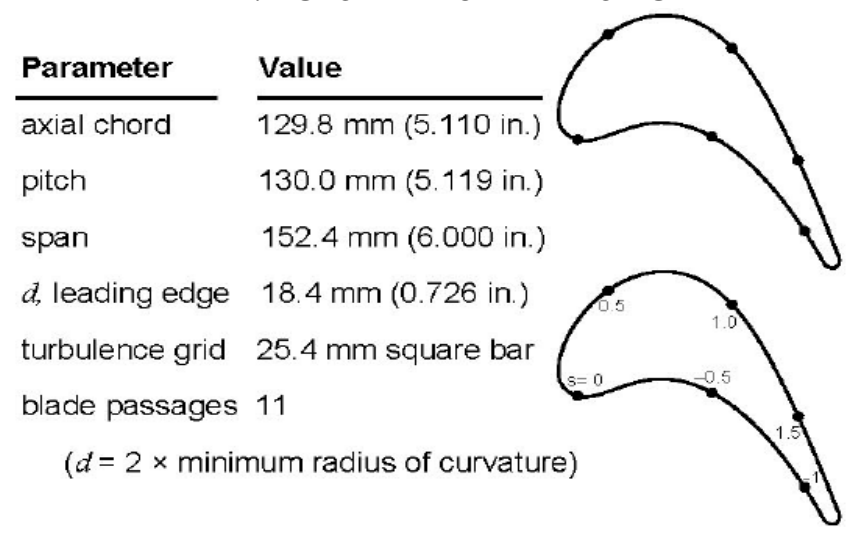




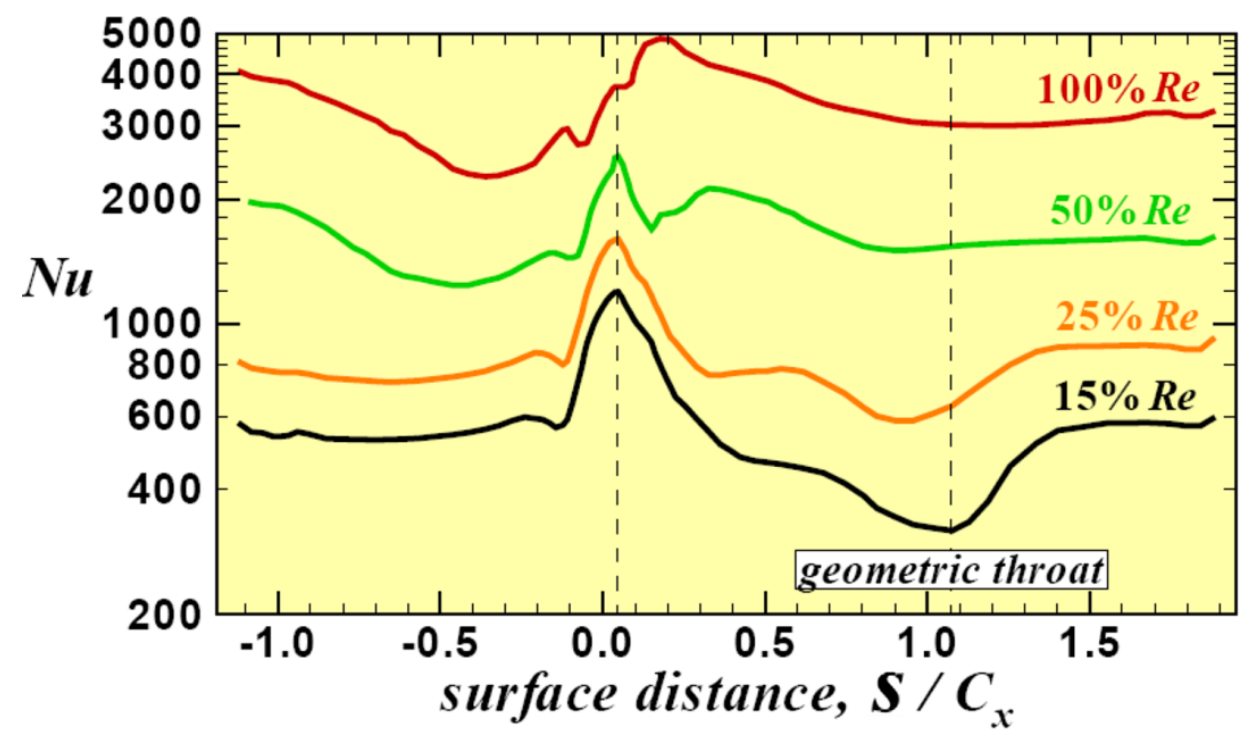

Figure 1.-Nusselt number variation for GE2 blade vs. wetted distance on the blade surface at mid-span for four different Reynolds numbers.

Figure 1, taken from Giel et al. (Ref. 5), clearly demonstrates the effect of Reynolds number on suction surface (positive $S / C_{x}$ values) flow transition as evidenced by steep increases in heat transfer on the suction side and by less gradual increases on the pressure side. The results for the two lowest Reynolds numbers of 15 percent design namely $\operatorname{Re}_{2}=375,000$ and 25 percent design $\operatorname{Re}_{2}=620,000$ show the most dramatic variation and are the lowest Reynolds numbers in that data set and are suitable for our purposes.

\section{Other Data}

The flat plate is a fundamental configuration for which any model must produce acceptable results before proceeding farther. As such, we supplemented the data for GE2 with flat plate laminar and turbulent heat transfer correlations presented in Reference 5 . The flat plate flow was started with a uniform flow upstream with a slip boundary condition. At $x=0$, a wall boundary condition at constant wall temperature is initiated. At the inlet the free stream turbulence was varied.

\section{Glenn-HT Computer Code}

The computer code used and modified in this work is the Glenn-HT code (Ref. 26). It can be described as follows:

Glenn-HT is a Fortran 90 code. It is designed to be a multi-physics code and presently is capable of performing solid conduction and compressible fluid flow. It is written in modular form and follows object oriented programming concepts.

The code uses a finite volume formulation to solve the unsteady compressible Navier-Stokes equations using a multigrid scheme and dual time-stepping. An explicit Runge-Kutta solver is used as a smoother. The code uses a general multi-block structured grid. The blocks can be arranged in an unstructured manner. The default solver uses a central difference convective scheme, $4^{\text {th }}$ order artificial dissipation with eigenvalue scaling which helps to dampen oscillations and $2^{\text {nd }}$ order differencing is used near shocks. A second order upwind scheme is also available. To raise the CFL limitation, residual smoothing is used. Residual smoothing was found to have deleterious effect on the convergence with Walters-Leylek turbulence model equations. They were computed without the use of residual smoothing on those equations. 


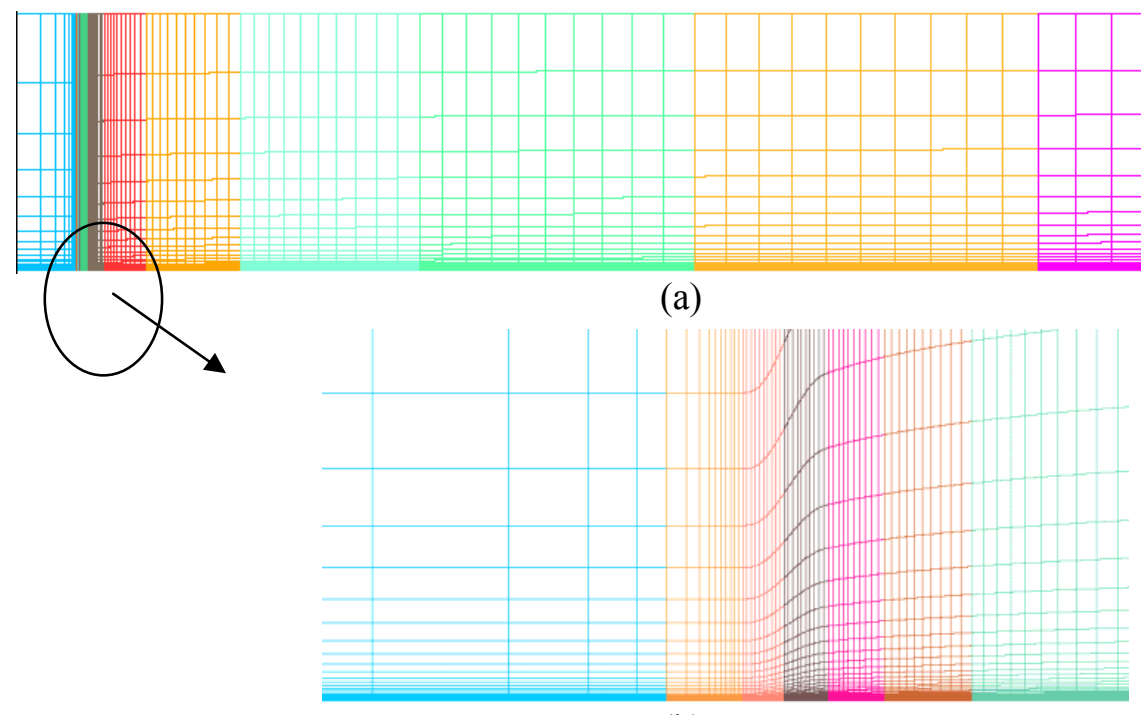

(b)

Figure 2.-(a) Grid for the two-dimensional grid and (b) near leading edge of the plate.

\section{Computational Grid}

For the transition modeling tests, a two-dimensional grid for a flat plate and both two-dimensional and three-dimensional grids for the GE2 geometry (Ref. 5) were generated.

The grids used for CFD computations in this work are generated using a commercial software tool called GridPro (Program Development Corporation). The software uses an elliptic solver to smooth an initial, algebraically generated, multi-block grid.

For the flat plate grid, as shown in Figure 2, the grid starts upstream of the flat plate. The grid is refined toward the leading edge (shown in Fig. 2(b)) in both direction. This is done so that the fast developing flow in the leading edge region can be resolved. The grid is highly refined in the cross-stream direction as well. The grid is generated in 16 blocks. Each block consists of a 16×64 point array in the streamwise $\times$ normal direction, respectively.

For the GE2 blade, taking advantage of the symmetry of the passage for the three-dimensional grid, only half of the span is gridded. The grid was constructed using 100 blocks for both the two-dimensional and three-dimensional cases that were generated. As is the practice with grid generation when using the software GridPro, an inviscid grid is generated first and subsequently viscous grid is generated using clustering. The grid was clustered near the blade and the endwall surfaces. The spacing was chosen such that the first grid line away from the wall was at a dimensionless wall distance $\left(y^{+}\right)$of near unity. Figures 3(a) and (b) show the two-dimensional and three-dimensional grids for the computations to follow. The inlet plane was situated to match the measurement stations in the experiment at an axial spacing of one axial chord upstream. The downstream boundary was placed at 1.5 axial chord distance downstream of the trailing edge.

The three-dimensional grid consisted of 608,000 grid points with 64 grid points used in the spanwise direction. The two-dimensional grid consisted of 9500 points. In the process of computations, it was decided that to ensure grid convergence, even finer grid was required. A very fine grid with a total number of cells of 2,313,984 cells with 92 cells in the spanwise direction was generated. In addition, a two-dimensional grid was also generated which consisted of 25000 cells. Coarse grid runs were made at various levels whereby the grid dimensions are divided by $2^{\text {level }}$. Each coarser level has 8 times fewer cells than the parent grid (in three-dimensional). The grid level of the finest grid is zero and a coarse grid with half the number of cells in each of the three directions is level $=1$ (Medium), and when level $=2$, the grid is referred to as coarse. The finest grid is generated and the code Glenn-HT performs the grid reduction and solution automatically. 


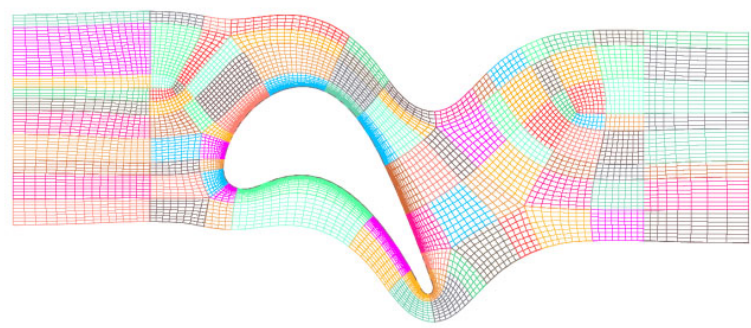

(a)

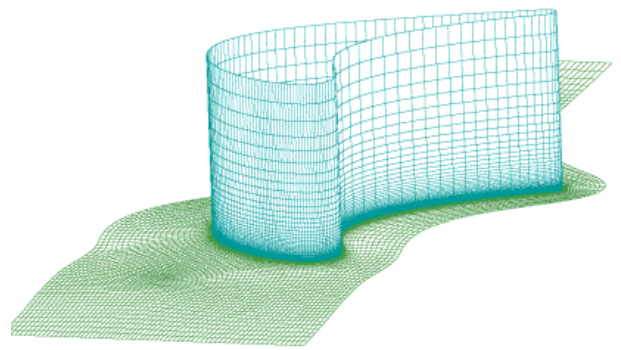

(b)

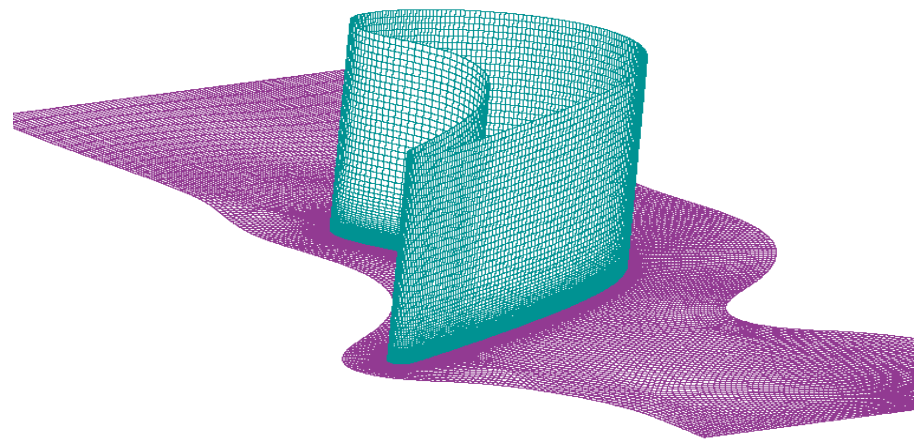

(c)

Figure 3.-(a) midspan grid and (b) the full three-dimensional grid and (c) very fine three-dimensional-grid.

\section{Flat Plate Validation}

Plots of $C_{f}$ (coefficient of friction) and Stanton number for flow over a flat plate are shown in Figures 4(a) and (b). The plot of Figure 4(a) shows the variation of friction factor, $C_{f}=\tau_{w} /\left(0.5 \rho \mathrm{u}_{\infty}{ }^{2}\right)$, or wall shear stress normalized by the dynamic pressure versus the local Reynolds number. Each figure presents two inlet turbulence intensities as computed on two different grid refinement levels. The lines show that the computed location of transition is dependent on the grid resolution but the levels for the turbulent values are well predicted. As shown in Figure 4(a), the results of $C_{f}$ show very good match to both the theoretically based laminar flow solutions and to measured turbulent flow values reported in textbooks such as (Ref. 27). The plot showing the variation of Stanton number with the local Reynolds number also shows a good match with the turbulent flow correlation. Agreement with the laminar flow heat transfer theory is imperfect showing enhancement in the laminar regime; a sign of a prolonged transition. The location of transition shows a movement upstream with increased turbulence intensity, which is physically correct.

The results appear to make physical sense and agreement with theory and correlations is such that we can turn our attention to the turbine blade cascade comparison of GE2 geometry. 

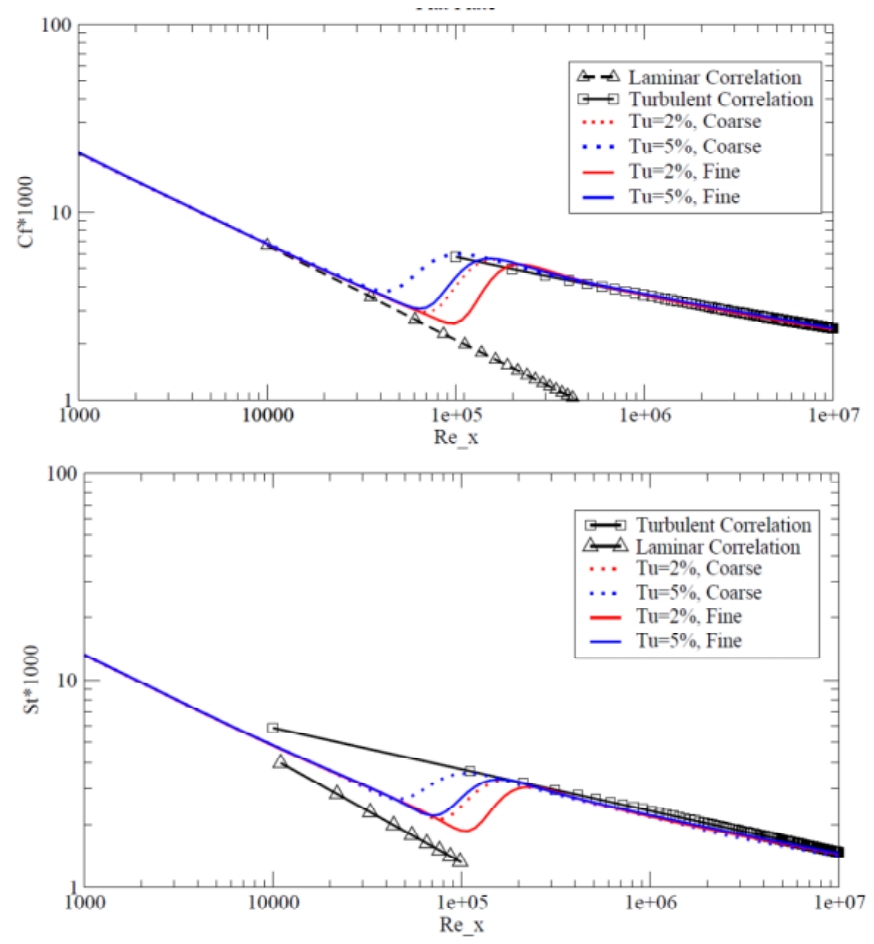

Figure 4.-(a) Friction factor and (b) Heat transfer on a flat plate; computations and comparison with data.

\section{GE2 Blade Comparisons}

Two and three-dimensional runs were made to compare with mid-span and off mid-span results of the GE2 experiment. Two Reynolds numbers are considered, a lower Reynolds number $\left(\operatorname{Re}_{2}\right)$ of 375,000 and a higher Reynolds number of 621,000 . At the inlet a turbulence intensity of 13 percent was specified which is the measured value at one axial chord upstream of the cascade. Computations were made at various levels of refinement to ensure grid convergence.

\section{Pressure}

Figure 5 shows the pressure distribution at the mid span on the blade. Two-dimensional and threedimensional results are shown. Three-dimensional results showed better agreement with data. This was expected because in the experiment, the hub endwall had a substantial incoming boundary layer and thus the pressure distribution from a three-dimensional computation should match the data better as it is the case.

\section{Nusselt Number}

In this section we present two-dimensional and three-dimensional results for heat transfer on the GE2 blade. In the plots of heat transfer to come, the ordinate is the Nusselt number and the abscissa is the dimensionless wetted distance on the blade surface. Because of the prismatic shape of the blade, there is no ambiguity in the definition. The origin is the stagnation point defined based on the inlet angle. The definition of Nusselt number used to represent the dimensionless rate of heat transfer comes from (Ref. 23) and is defined as:

$$
N u_{C X}=h C_{X / k}
$$



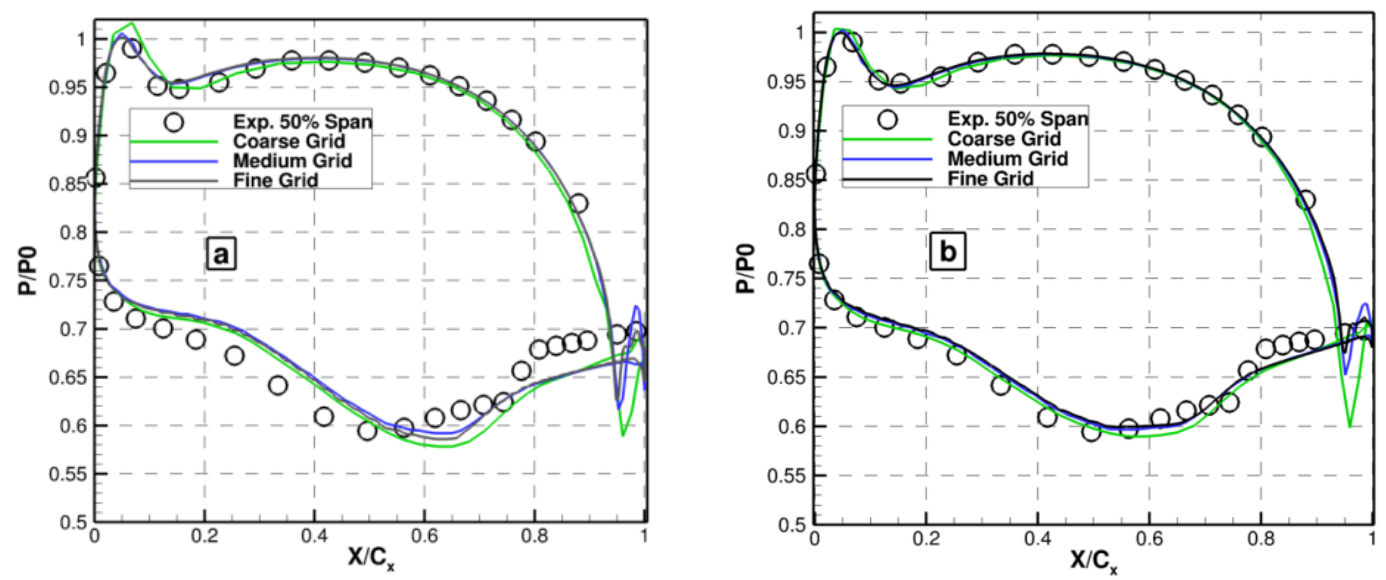

Figure 5.-(a) Two-dimensional and (b) Three-dimensional computation of pressure distribution at the midspan of GE2 blade and comparison with data from Reference 5.

Where $h$ is:

$$
h=\frac{q_{w}}{\left(T_{a w}-T_{w}\right)}
$$

The $T_{a w}$ in the experiment reported in Reference 9, was computed by an expression involving the turbulent recovery factor computed from,

$$
r=\operatorname{Pr}^{1 / 3}
$$

Using this relationship, the equation for the recovery temperature is:

$$
T_{a w}=T_{s}\left(1+r \frac{\gamma-1}{2} M^{2}\right)
$$

In the post-processing step, the local isentropic surface Mach number based on the local pressure ratio is computed and used to compute the adiabatic wall temperature.

\section{k- $\omega$ model}

Figure 6 shows the midspan distributions from a three-dimensional computation of heat transfer with the low Reynolds number $k-\omega$ model (Ref. 25). The plot shows that the flow transitions early near the leading edge while the data shows that the flow is transitional. Early transition leads to attached flow where the flow may instead be separated and in general leads to miscalculation of losses.

Below, we show computations performed with the Walters-Leylek three equation model for two and three-dimensional simulations. 


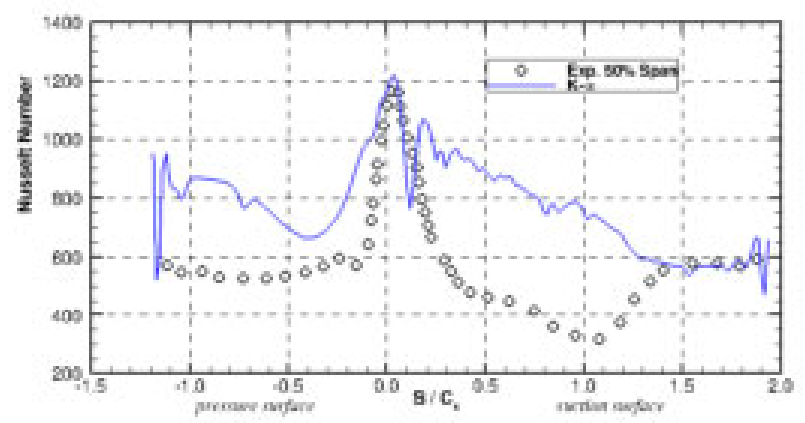

Figure 6.-Three-dimensional computation of midspan Nusselt number against data of Reference 5 with $k-\omega$ model, $\mathrm{Re}_{2}=375 \mathrm{k}$.

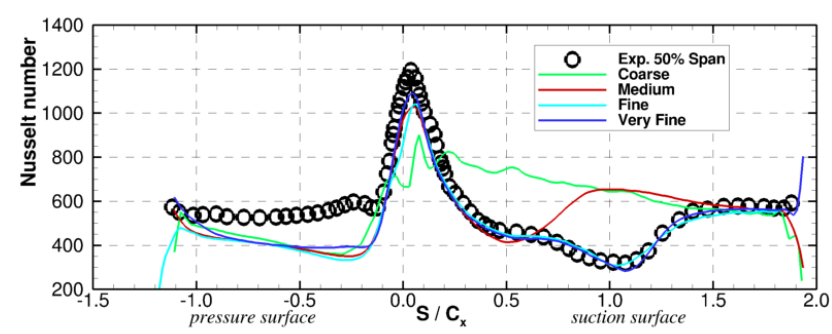

Figure 7.-Two-dimensional computation of Nusselt number against data of Giel et al. (Ref. 5), $\mathrm{Re}_{2}=375 \mathrm{k}$.

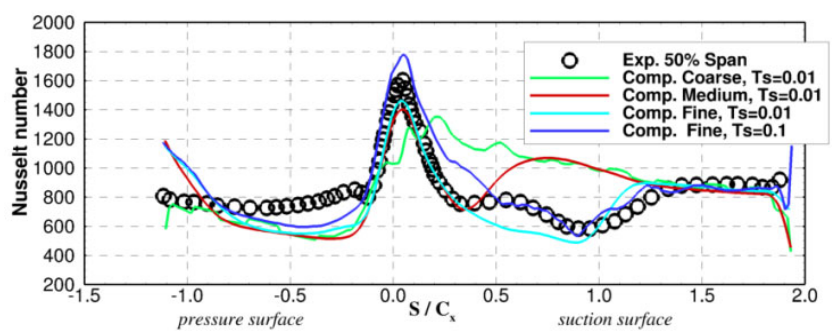

Figure 8.-Two-dimensional computation of Nusselt number against data of Giel et al. (Ref. 5), $R_{2}=621 \mathrm{k}$.

\section{Walters-Leylek Model}

\section{Two-Dimensional Runs}

Figure 7 shows heat transfer results obtained for an exit Reynolds number of 375,000. A series of grid resolutions from coarse to fine grid were used. A turbulence intensity of 13 percent and length scale of 1 percent of chord were specified at the upstream boundary. Grid convergence shows that fine grid (9500 points in two-dimensional) is needed for spatial convergence. The "fine" and "very fine" grids have, as described earlier, 9500 and 25,000 points. The predicted suction side heat transfer, similar to the experimental data, exhibits transitional behavior for which the location and extent of the transition agrees with the data. On the pressure side, the agreement is not as good. A slightly earlier transition on the pressure side may have resulted in better agreement with the pressure side heat transfer.

Figure 8 shows the heat transfer prediction for the higher Reynolds number $\left(\operatorname{Re}_{2}\right)$ of 621,000 . The agreement with the data is similar to the lower Reynolds number case although on the pressure side there is a steep rise in heat transfer near the trailing edge. 


\section{Three-Dimensional Runs}

The midspan Nusselt number prediction for $\mathrm{Re}_{2}=375,000$ is shown in Figure 9. An inlet turbulence of 13 percent as measured by the experiment and an inlet boundary layer thickness of 37 percent of halfspan is specified at the inlet. A length scale of 1 percent of span was imposed at the inlet. The computations were carried out on three grids of varying densities. The same grids shown in Figures 3(b) and (c) are used for three-dimensional computations. The grid in Figure 3(c) (2.3e6 grid points) was used for coarsening (resulting in the medium and coarse grids) while the grid in Figure 3(b) designated as "Fine" (610,000 grid points) was used to verify convergence. The fine grid appears to be adequate for the three-dimensional computations. The magnitude of Nusselt number at midspan is seen to be underpredicted and does not rise to the fully turbulent values though the location of transition is well predicted.

A 10 percent turbulent length scale (dot-dashed line) was also tested with the medium grid. The results at midspan, shown in Figure 9, do not indicate an improvement.

Figure 10 presents comparison with experimental data for the 15,25 , and 50 percent span for the two finest grids. Comparisons are provided to show that using the "Fine" grid, grid convergence has been achieved for the three spanwise locations. For all the span locations, heat transfer in the fully turbulent regime downstream on the suction side is under-predicted. The transition locations, however, are quite accurately predicted. It is observed that the two-dimensional computations show good agreement on the suction surface for the fully turbulent regime downstream of transition. It may be argued that the threedimensional computations react strongly to the inlet boundary layer as evidenced by the convergence of the streamlines toward midspan. Figure 11 shows the Nusselt number distribution on the blade surface and clearly shows the three-dimensional variation with the conditions stipulated by the experiment. A case with an inlet boundary layer of half the thickness was run $(\delta / 2)$. As shown in Figure 12, on the suction side, the midspan heat transfer increases with the reduction in inlet boundary layer thickness.

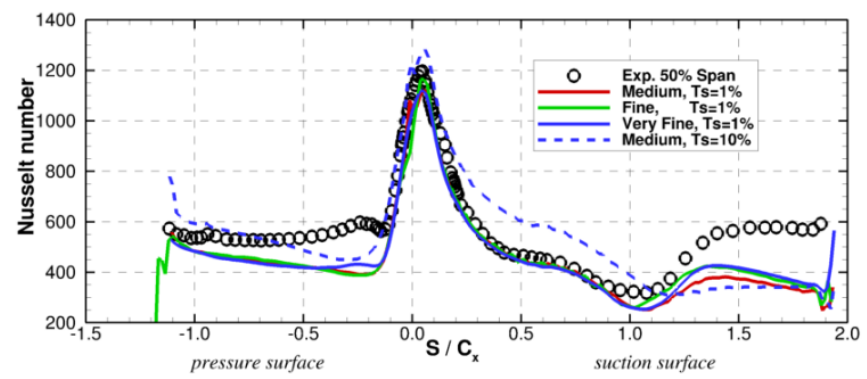

Figure 9.-Effect of the applied turbulent length scale at the inlet against data of Giel et al. (Ref. 5), $\mathrm{Re}_{2}=375 \mathrm{k}$.

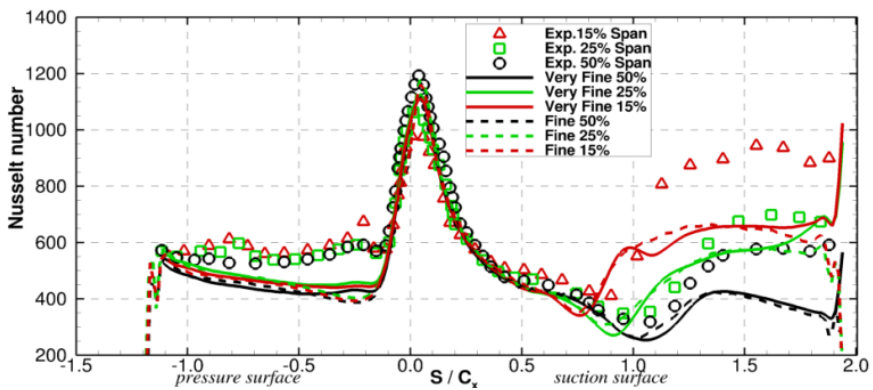

Figure 10.-Three-dimensional computation of Nusselt number and comparison with data from Reference 5, $\mathrm{Re}_{2}=375 \mathrm{k}$ 


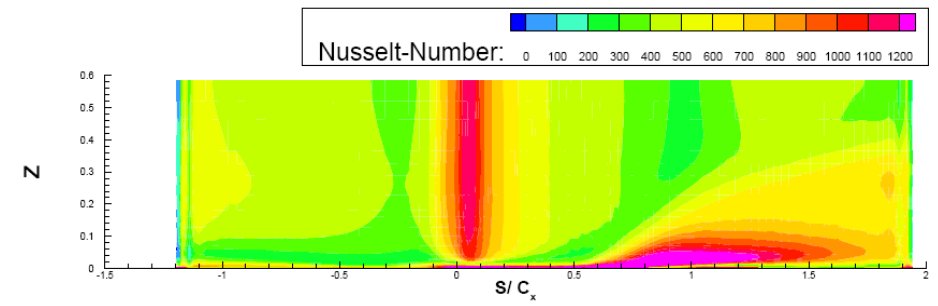

Figure 11.-Contour plot of Nusselt number over the surface of the vane, $\operatorname{Re}_{2}=375 \mathrm{k}$.

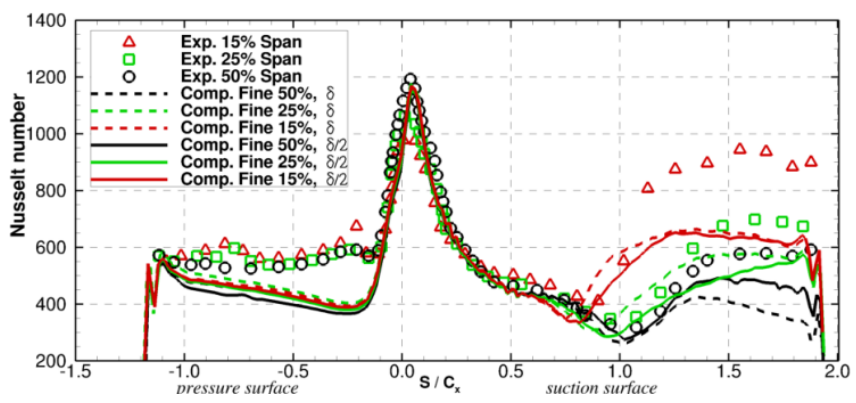

Figure 12.-Three-dimensional computation of Nusselt number and comparison with data from Reference 5, $\mathrm{Re}_{2}=375 \mathrm{k}$.

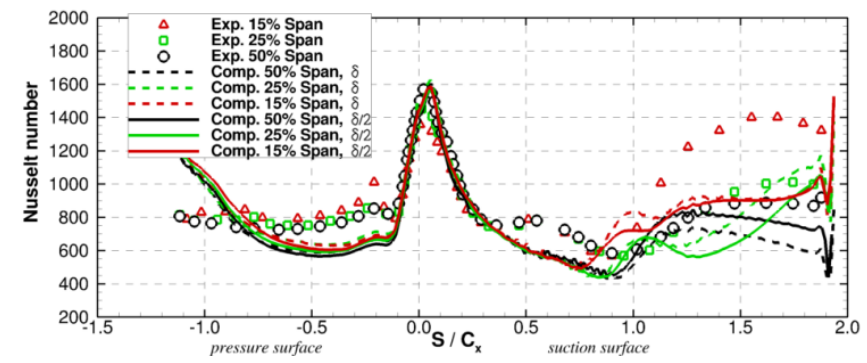

Figure 13.-Three-dimensional computation of Nusselt number and comparison with data from Reference 5 , $\mathrm{Re}_{2}=621 \mathrm{k}$.

At 25 percent span the trend is the opposite at the midspan with boundary layer thickness. This appears to be a result of shifting of the transition point further downstream and at 15 percent no substantial change is demonstrated. The pressure side results do not strongly react to this change. In all cases the location of transition on the suction side for all spanwise locations is well-predicted and the midspan heat transfer agreement is improved by reducing the boundary layer thickness.

Figure 13 shows the results with the higher Reynolds number of $\operatorname{Re}_{2}=621,000$. The same trends are observed. The one other trend in the computations is the sudden rise of heat transfer near the trailing edge on the pressure side which is absent in the data but was also present in the two-dimensional computations. This trend is observable in the data but at a higher Reynolds number as evident in Figure 1. 


\section{Summary of Heat Transfer Predictions}

The ability to accurately model transition was measured through simulation of blade heat transfer. Two and three-dimensional simulations of flow and the resulting heat transfer distributions on turbine blades were performed. Two-dimensional runs show excellent agreement with the data for the lower Reynolds number and good agreement for the higher Reynolds number case. Three-dimensional runs predict correctly the transition location on the suction side. For the Variable Speed Power Turbine, the Reynolds numbers are going to be low and the location of transition point or laminar flow separation will be important in determining the losses in the blade row. Based on the present simulations, it is concluded that the present transition modeling will perform successfully for the prediction of losses.

\section{Numerical Prediction of Losses}

At this point, we are equipped with a model verified to be accurate for prediction of transition in three-dimensional flows. We now turn our attention to the computation of the "loss bucket" for the candidate case. The candidate case is the $E^{3}$ tip profile cascade. Measurements of wake profile and losses for this geometry are in progress at NASA Glenn Research Center's Transonic Blade Cascade. Surveys of exit total pressure are to be compiled for a wide variation of incidence angles, Reynolds numbers and exit Mach numbers. The data will be used to help verify the loss prediction capability for a wide range of incidence angles. In the sections to follow, we will describe the numerical setup and computed wake profile and loss bucket for a single Reynolds number of 65,000 .

\section{Computation Details}

In the next section the grid produced for this geometry is defined. For the computations at the inlet a boundary layer thickness equivalent to 25 percent tunnel span was specified. Angles at the inlet were varied to match the case being computed. The inlet turbulence intensity was specified to be equal to 1 percent and the turbulence length scale was set at the inlet to be one percent of the span. At the exit a pressure ratio of 0.925 was specified.

\section{Grid for $E^{3}$ Blade Tip Section}

Experience shows that a fine grid would be required for loss computations. A grid with $2.75 \mathrm{e} 6$ points, as shown in Figure 14, was generated for this purpose. A two-dimensional section of the grid being stacked 81 times contains 34,000 grid points. As was discussed in connection with GE2 blade gridding, the upstream boundary of the grid was matched to the experimental upstream measuring station. Symmetry is used so that the computational domain extends to midspan.

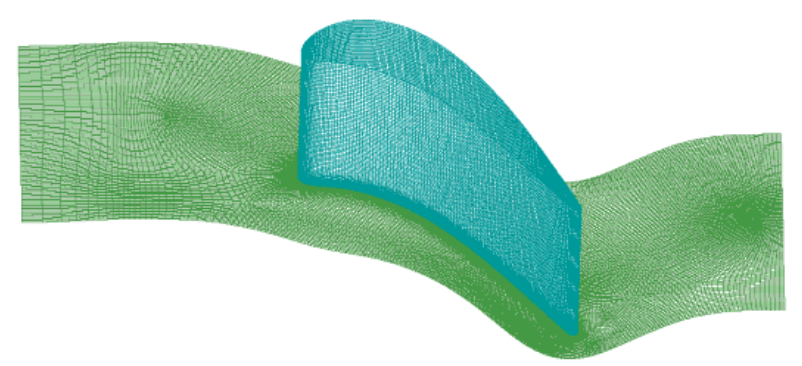

Figure 14.-Three-dimensional blade grid of the $E^{3}$ blade tip section cascade taking advantage of symmetry at midspan. 


\section{Computed Loss Profiles Downstream}

The loss coefficient $C_{p}$ was computed as:

$$
C_{p}=\frac{P_{t_{-} i n}-P_{t_{-} y}}{P_{t_{-} i n}-P_{s_{-} 2}}
$$

Here the subscripts " $t$ " signifies total value and the subscripts " $y$ " and "in" signify local and inlet values. At the inlet, the incoming flow had a turbulence intensity of 1 percent and the boundary layer thickness was 25 percent of half-span. The Reynolds number for the computed cases, based on the axial momentum and the chord, was 65,000 . A pressure ratio of 0.925 was specified. Losses are to be measured at the midspan of the channel over a range of incidence angles. Losses are expected to be due to secondary flows and separation. Figure 15 shows the computed midspan loss coefficient at a station located at $1.086 \times C_{x}$ downstream of the leading edge of the cascade. The flow angle of $38.8^{\circ}$ is the baseline angle and the incidence is measured from that angle. Figure 15 shows the wake loss to increase proceeding from the angle of $28.8^{\circ}$ (or incidence angle of $-10^{\circ}$ ) to higher incidence angles. While the difference in losses between $-10^{\circ}$ and 0 is rather small, the difference in losses between 0 and $10^{\circ}$ is substantial and for the $+20^{\circ}$ the wake shows very little "free stream" for which the loss coefficient would be zero. The loss coefficient plot in Figure 15 shows negative values of $C_{p}$ which are unphysical and purely related to the numerical scheme.

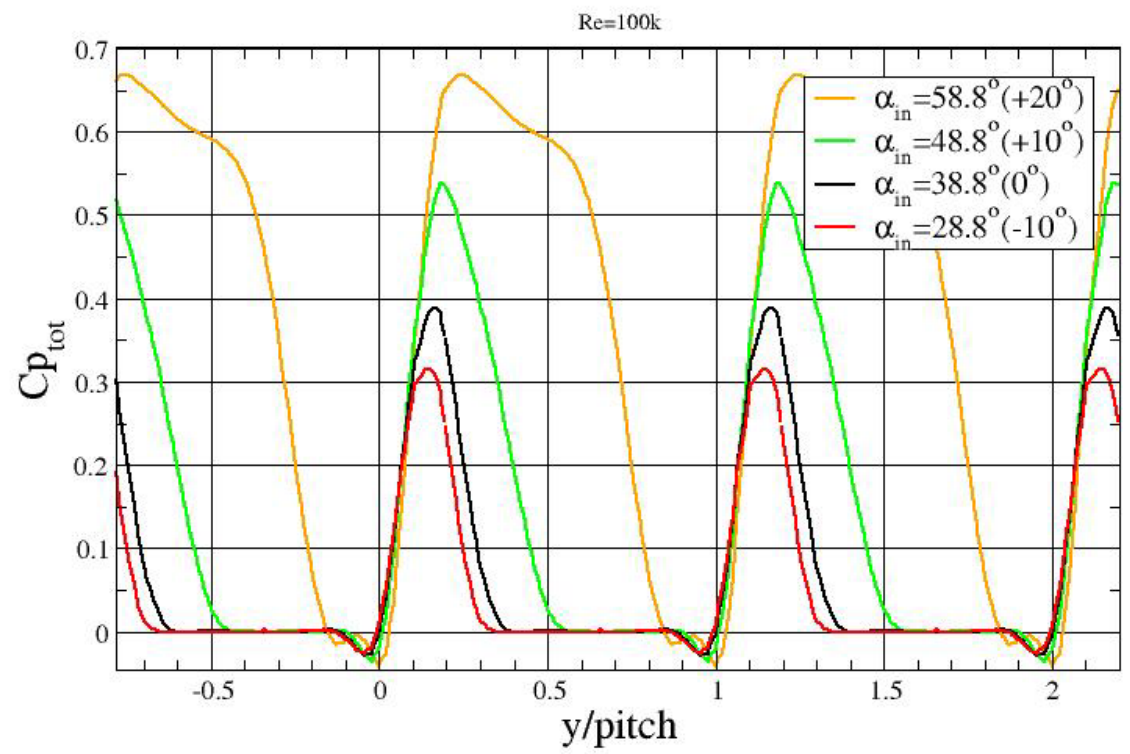

Figure 15.-Predicted total pressure loss coefficient at various flow angles (incidences). 
To better understand the losses and the sources of loss we refer to Figure 16. In that figure, the loss coefficient contours downstream of the blades are shown (at 1.086 axial chord) for incidence angles of $-75,-25,0$, and $+20^{\circ}$ shown in a clockwise order. Note that the spanwise domain is from the hub to the symmetry plane. Areas of large total pressure loss can be identified for each case. All cases show large losses in the wake as well as those associated with the wake/endwall interaction. Figure 17 shows the flow patterns for each incidence angle of Figure 16. Vortex cores are captured by plotting iso-surfaces of loss coefficient. The patterns of $C_{p}$ follow, for the most part, the vortical structures within the passage. The levels are chosen so that the most illuminating picture of the flow may be presented. The iso-surfaces are colored by density to allow better visualization. Some of the large loss areas from Figure 16 can be matched to vortex cores. Matching of the loss cores to the vortex can be done using the sign of the vortex. For case (a) the largest loss near the endwall is due to the interaction of endwall boundary layer and the horseshoe/passage vortex, which stays near the endwall due to the unloading of the blades (17(a)). The mid-passage increase in loss for case (a) is due to large flow separation on the pressure side (cove separation) which starts up as a spanwise vortex but turns into a streamwise vortex near midspan. For the other three cases the midspan loss may be due to the suction side leg of horseshoe vortex. One area of large losses appears as a bulge in the loss contours, in the wake for case (b) and better formed local maxima for (c) and (d) are due to the combined effect of horseshoe and passage vortices. As the loading increases with the incidence, the local maximum gets larger and wider.

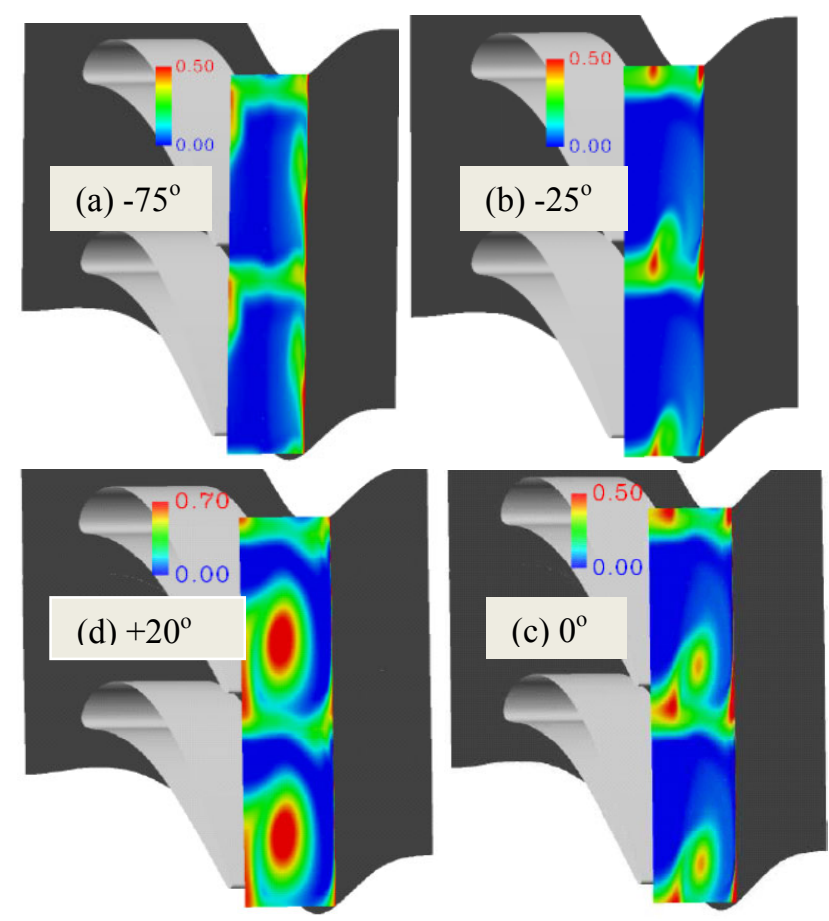

Figure 16.-Total pressure loss contours (clockwise) from top-left for incidences of (a) -75 , (b) -25 , (c) zero, and (d) $+20^{\circ}$. Note the scale change. 


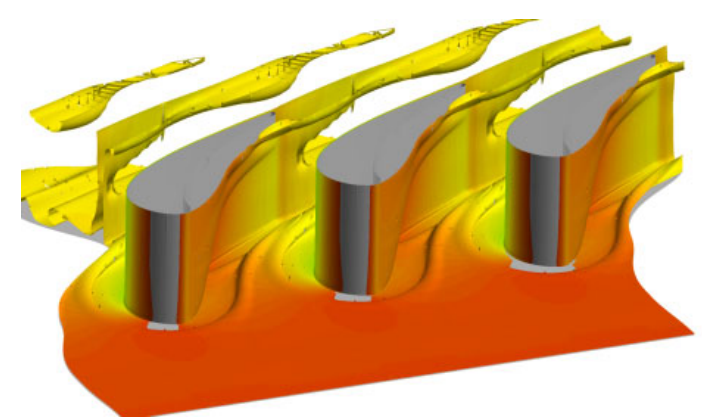

(a) $-75^{\circ}$

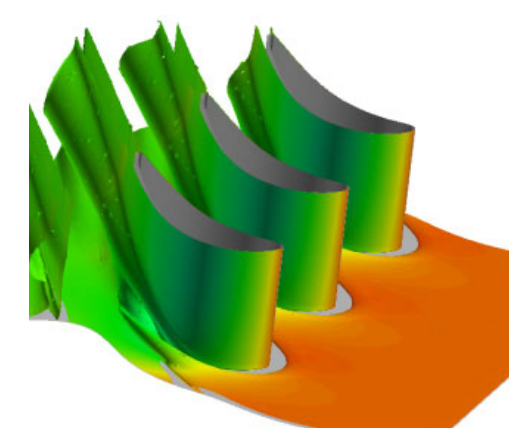

(b) $-25^{\circ}$

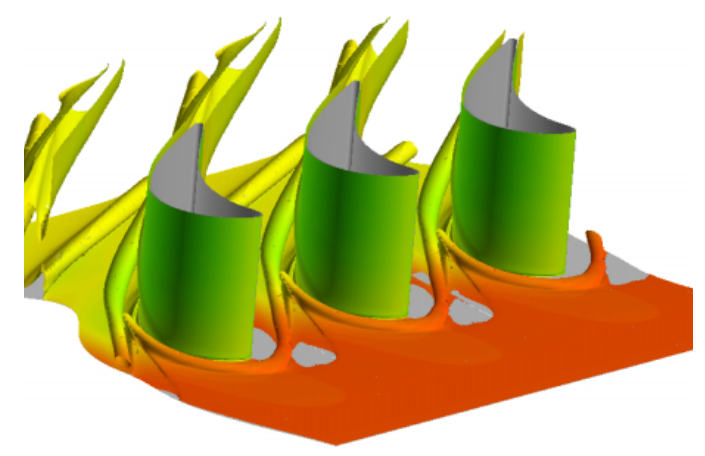

(c) $0^{\circ}$

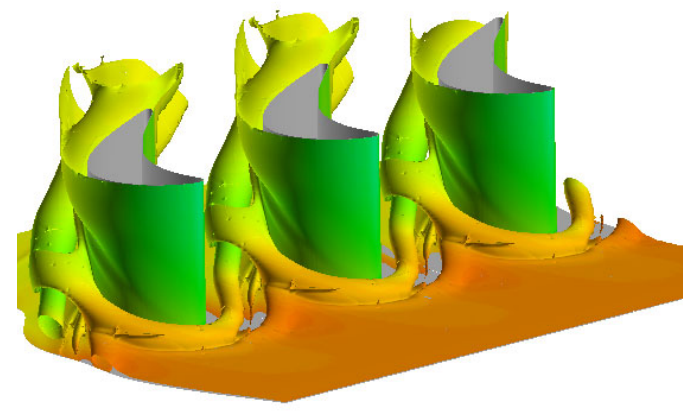

$$
\text { (d) }+20^{\circ}
$$

Figure 17.-Loss coefficient iso-surfaces for the given incidence angles of $+20^{\circ}, 0^{\circ},-25^{\circ}$, and $-75^{\circ}$. 


\section{Integrated Results}

Losses for the cases discussed above, as well as additional computations for other incidence angles were integrated and averaged over the exit channel area at the measuring station $\left(x=1.086 \times C_{x}\right)$ in order to compute an average loss coefficient. The resulting line plot of the integrated losses against the incidence angle, as shown in Figure 18, is what is referred to as a loss bucket. The results show a rather flat region for a wide range of incidence angles. Welch (Ref. 4) presented the loss bucket for high-lift rotor blading of Clark et al. (Ref. 29) showing cruise (design air angles) and take-off ( $-50^{\circ}$ incidence) operation. That plot is reproduced here in Figure 19 so as to allow qualitative comparison with our computed results. The computations in Reference 29 were performed using a two-dimensional code with the $k-\omega$ low Reynolds number turbulence model. Results presented herein include the full threedimensional losses, and include endwall and secondary flow losses which contribute to the integrated values. The agreement appears to be reasonable. It bears reminding the reader that the inlet boundary layer thickness for our computations was quite substantial.

Loss Coefficient vs. Incidence Angle Axial Plane at $1.086 * \mathrm{C}_{\mathrm{x}}, \mathrm{Re}=100 \mathrm{k}$

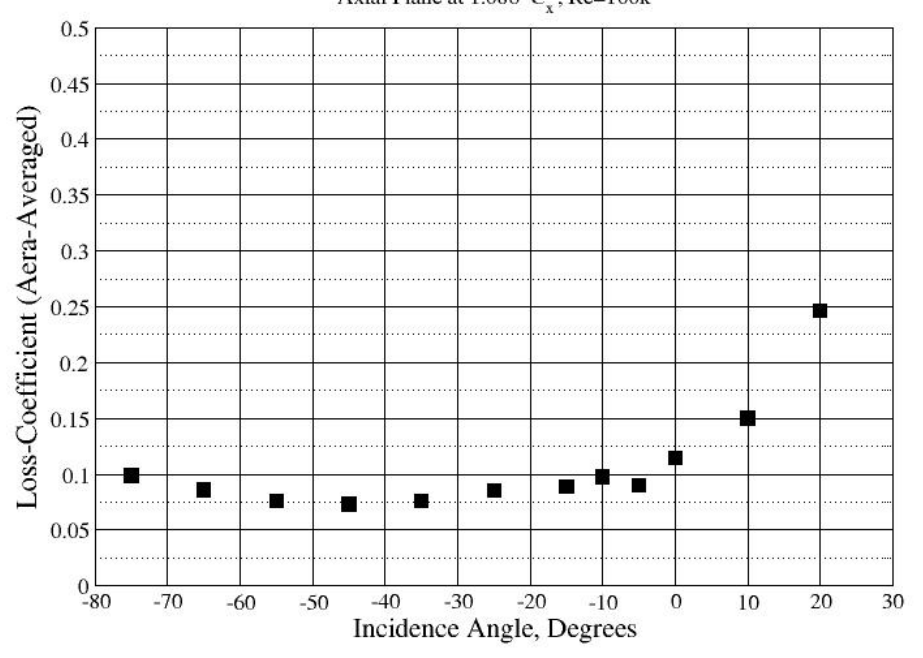

Figure 18.--Loss bucket formed from the three-dimensional loss integration of Figure 16.

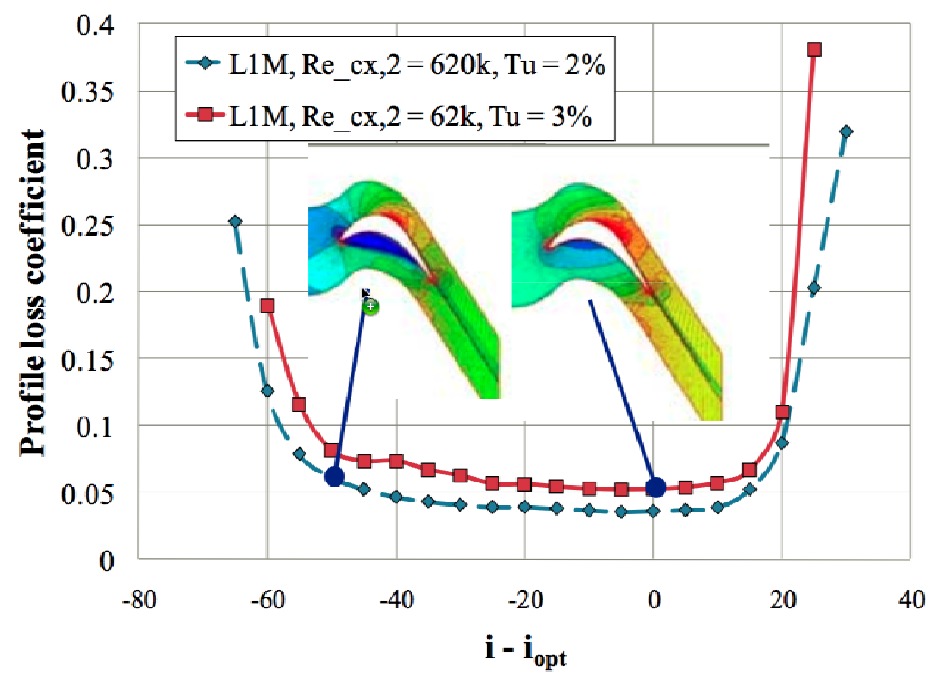

Figure 19.-Loss bucket from Welch (Ref. 4). 


\section{Summary and Conclusions}

For the Variable Speed Power Turbine study, the flow transition/separation has been identified as an important process. Computational schemes need to address this question if the losses are to be predicted correctly.

The transition model of Walters and Leylek (Ref. 18) was implemented in Glenn-HT code, which is a three-dimensional solver. This model uses a phenomenological model of the bypass transition and allows for natural transition and separated flow. The ability to predict transition was tested by applying to the model to a flat plate and a turbine blade test case (Ref. 5) for heat transfer. Two-dimensional and threedimensional tests were performed. The location of transition was successfully predicted on the suction side and the transition modeling on the pressure side was reasonable. The model was then employed to compute the $\mathrm{E}^{3}$ tip profile cascade to be tested in the Transonic Turbine Blade Cascade Tunnel at NASA Glenn Research Center. The losses were computed for a wide range of incidence angles and sources of loss were identified. Losses are generated by the endwall and blade boundary layer as well as transported and augmented by the horseshoe and passage vortices. At high negative incidences, pressure side separation and roll up of the resulting vortex into a streamwise vortex is indicated. These vortices strengthen and widen as the loading on the blades increases with the incidence angle. The loss bucket shows a wide region of nearly flat losses between the two large positive and negative incidence angle. Data for the wake losses will be forthcoming and the accuracy of the results will be measured by those data.

\section{References}

1. Gier, J.; Franke, M., Hübner, N., Shröder, T., 2008, "Designing LP Turbines for Optimized Airfoil Lift," ASME-GT2008-51101.

2. Haselbach, F., Schiffer, H.-P., Horsman, M., Dressen, S., Harvey, N., Read, S., 2002, "The Application of Ultra High Lift Blading in the BR715 LP Turbine," ASME Journal of Turbomachinery Volume 124, 45-51.

3. Hourmouziadis, J., 1989, “Aerodynamic Design of Low Pressure Turbines," in Blading Design for Axial Turbomachines, AGARD-LS-167, pp. 8-1 to 8-40.

4. Welch, G.E., 2011, "Computational Assessment of the Aerodynamic Performance of a VariableSpeed Power Turbine for Large Civil Tilt-Rotor Application,” Proceedings AHS Forum 67, Virginia Beach, VA, May 3-5, 2011; also NASA/TM-2011-217124.

5. Giel, Paul W., Boyle, Robert J. and, Bunker, Ronald S, 2004, "Measurements and Predictions of Heat Transfer on a Transonic Turbine Cascade," Journal of Turbomachinery, Volume 126, Issue 1, 110.

6. Timko, L.P., 1984, "Energy Efficient Engine High Pressure Turbine Component Test Performance Report," NASA CR-168289.

7. Boyle, R.J., 1991, "Navier-Stokes Analysis of Turbine Blade Heat Transfer," ASME Journal of Turbomachinery, Volume 113, Issue 3, 392.

8. Chima, R.V., Giel, P.W., and Boyle, R.J., 1993, “An Algebraic Turbulence Model for ThreeDimensional Viscous Flows," AIAA paper 93-0083.

9. Boyle, R.J. and Simon, F.F., 1991, "Mach Number Effects on Turbine Blade Transition Length Prediction," ASME Journal of Turbomachinery, Volume 121, Issue 4, 694.

10. Ameri, Ali A., Arnone, A, 1996, "Transition Modeling Effects on Turbine Rotor Heat Transfer," ASME Journal of Turbomachinery, 118, No. 2, pp. 307-313, Apr. 1996.

11. Mayle, Robert Edward, 1991, "The Role of Laminar-Turbulent Transition in Gas Turbine Engines," J. Turbomach., October 1991, Volume 113, Issue 4, 509.

12. Savill, A.M., 1993, "Some Recent Progress in Turbulence Modeling of Bypass Transition," in Near Wall Turbulent Flows, Edited by RMC. So, C.G. Speziale and B.E. Launder.

13. Suzen, Y.B., and Huang, P.G., 2000, "Modeling of Flow Transition Using an Intermittency Transport Equation," ASME Journal of Fluids Eng., 122, pp. 273-284. 
14. Steelant, J. and Dick, E., 1996, "Modeling of Bypass Transition with Conditioned Navier-Stokes Equations Couple to an Intermittency Transport Equation," Int. J. Numerical Methods Fluids, Volume 23, Issue 3, pages 193-220.

15. Menter, F.R., Langtry, R.B., Volker, S., Huang, P. G., 2005, “Transition Modeling for General Purpose CFD Code," in, ERCOFTAC International Symposium on Engineering Turbulence Modeling and Measurements.

16. Suluksna, Keerati, Dechaumphaib, Pramote and Juntasaro, Ekachai, 2009, "Correlations for modeling transitional boundary layers under influences of freestream turbulence and pressure gradient," International Journal of Heat and Fluid Flow, Volume 30, Issue 1, February 2009, Pages 66-75.

17. Walters, D. Keith and Leylek, James H. , 2004, "A New Model for Boundary Layer Transition Using a Single-Point RANS Approach,” ASME Journal of Turbomachinery, Volume 126, Issue 1, 193.

18. Walters, D. Keith and Leylek, James H., 2005, "Computational Fluid Dynamics Study of WakeInduced Transition on a Compressor-Like Flat Plate," ASME Journal of Turbomachinery, Volume 127, Issue 1, 52 (12 pages).

19. Cutrone, L., De Palma, P., Pascazio, G., Napolitano, M., 2008, "Predicting transition in two- and three-dimensional separated flows," Int. Journal of Heat and Fluid Flow, Volume 29, Pages 504526.

20. Pacciani R., Marconcini M., Fadai-Ghotbi A., Lardeau S., Leschziner, M.A., 2011, "Calculation of High-Lift Cascades in Low Pressure Turbine Conditions Using a Three-Equation Model," ASME Journal of Turbomachinery, 133, 031016 (2011). ISSN 0889-504X.

21. Volino, R.J., 1998, "A New Model for Free-Stream Turbulence Effects on Boundary Layers," ASME Journal of Turbomachinery, 120, pp. 613-620.

22. Moss, R.W. and Oldfield, M.L.G. 1996, "Effect of Free-Stream Turbulence on Flat-Plate Heat Flux Signals: Spectra and Eddy Transport Velocities," ASME Journal of Turbomachinery, Volume 118, Issue 3, 461.

23. Bradshaw, P., 1994, "Turbulence: The Chief Outstanding Difficulty of Our Subject," Exp. Fluids, 16, pp. 203-216.

24. Volino, R.J., and Simon, T.W., 1997, "Boundary Layer Transition Under High Free-Stream Turbulence and Strong Acceleration Conditions: Part 2-Turbulent Transport Results," ASME Journal of Heat Transfer, 119, pp. 427-432.

25. Mayle, R.E., and Schulz, A., 1997, "The Path to Predicting Bypass Transition," ASME Journal of Turbomachinery, 119, pp. 405-411.

26. Steinthorsson, E., Liou, M.S., and Povinelli, L.A., 1993, "Development of an Explicit Multiblock/Multigrid Flow Solver for Viscous Flows in Complex Geometries," AIAA-93-2380.

27. Fundamentals of Heat Transfer, by Incropera, Frank P.; DeWitt, David P. New York: Wiley, c1981.

28. Wilcox, D.C., Turbulence Modeling for CFD, 3rd edition, DCW Industries, Inc., La Canada CA, 2006.

29. Clark, J.P., Koch, P.J., Ooten, M.K., Johnson, J.J., Dagg, J., McQuilling, M.W., Huber, F., and Johnson, P.D, "Design of Turbine Components to Answer Research Questions in Unsteady Aerodynamics and Heat Transfer," AFRL-RZ-WP-TR-2009-2180, (Internal Report) Sept. 2009. 


\begin{tabular}{|c|c|c|}
\hline \multicolumn{2}{|c|}{ REPORT DOCUMENTATION PAGE } & $\begin{array}{l}\text { Form Approved } \\
\text { OMB No. 0704-0188 }\end{array}$ \\
\hline \multicolumn{3}{|c|}{ 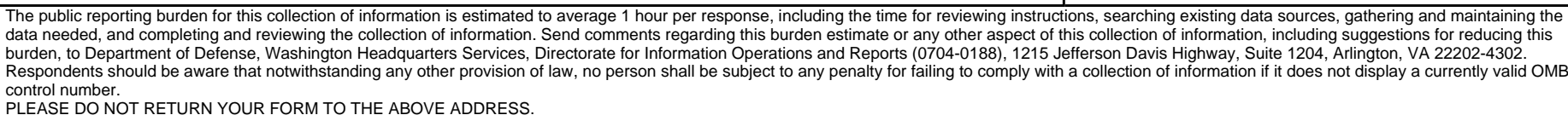 } \\
\hline $\begin{array}{l}\text { 1. REPORT DATE (DD-MM-YYYY) } \\
01-05-2012\end{array}$ & $\begin{array}{l}\text { 2. REPORT TYPE } \\
\text { Final Contractor Report }\end{array}$ & 3. DATES COVERED (From - To) \\
\hline \multirow{3}{*}{\multicolumn{2}{|c|}{$\begin{array}{l}\text { 4. TITLE AND SUBTITLE } \\
\text { Use of Transition Modeling to Enable the Computation of Losses for Variable-Speed Power } \\
\text { Turbine }\end{array}$}} & $\begin{array}{l}\text { 5a. CONTRACT NUMBER } \\
\text { NNC06BA07B }\end{array}$ \\
\hline & & 5b. GRANT NUMBER \\
\hline & & 5c. PROGRAM ELEMENT NUMBER \\
\hline \multirow{3}{*}{\multicolumn{2}{|c|}{$\begin{array}{l}\text { 6. AUTHOR(S) } \\
\text { Ameri, Ali, A. }\end{array}$}} & 5d. PROJECT NUMBER \\
\hline & & $\begin{array}{l}\text { 5e. TASK NUMBER } \\
\text { NNC10E420T-0 }\end{array}$ \\
\hline & & $\begin{array}{l}\text { 5f. WORK UNIT NUMBER } \\
\text { WBS 877868.02.07.03.01.02.01 }\end{array}$ \\
\hline \multicolumn{2}{|c|}{$\begin{array}{l}\text { 7. PERFORMING ORGANIZATION NAME(S) AND ADDRESS(ES) } \\
\text { Ohio State University }\end{array}$} & $\begin{array}{l}\text { 8. PERFORMING ORGANIZATION } \\
\text { REPORT NUMBER } \\
\text { E-18128 }\end{array}$ \\
\hline \multirow{2}{*}{\multicolumn{2}{|c|}{$\begin{array}{l}\text { 9. SPONSORING/MONITORING AGENCY NAME(S) AND ADDRESS(ES) } \\
\text { National Aeronautics and Space Administration } \\
\text { Washington, DC 20546-0001 }\end{array}$}} & $\begin{array}{l}\text { 10. SPONSORING/MONITOR'S } \\
\text { ACRONYM(S) } \\
\text { NASA }\end{array}$ \\
\hline & & $\begin{array}{l}\text { 11. SPONSORING/MONITORING } \\
\text { REPORT NUMBER } \\
\text { NASA/CR-2012-217435 }\end{array}$ \\
\hline \multicolumn{3}{|c|}{$\begin{array}{l}\text { 12. DISTRIBUTION/AVAILABILITY STATEMENT } \\
\text { Unclassified-Unlimited } \\
\text { Subject Categories: } 07 \text { and } 34 \\
\text { Available electronically at http://www.sti.nasa.gov } \\
\text { This publication is available from the NASA Center for AeroSpace Information, 443-757-5802 }\end{array}$} \\
\hline
\end{tabular}

\section{SUPPLEMENTARY NOTES}

\section{ABSTRACT}

To investigate the penalties associated with using a variable speed power turbine (VSPT) in a rotorcraft capable of vertical takeoff and landing, various analysis tools are required. Such analysis tools must be able to model the flow accurately within the operating envelope of VSPT. For power turbines low Reynolds numbers and a wide range of the incidence angles, positive and negative, due to the variation in the shaft speed at relatively fixed corrected flows, characterize this envelope. The flow in the turbine passage is expected to be transitional and separated at high incidence. The turbulence model of Walters and Leylek was implemented in the NASA Glenn-HT code to enable a more accurate analysis of such flows. Two-dimensional heat transfer predictions of flat plate flow and two-dimensional and three-dimensional heat transfer predictions on a turbine blade were performed and reported herein. Heat transfer computations were performed because it is a good marker for transition. The final goal is to be able to compute the aerodynamic losses. Armed with the new transition model, total pressure losses for three-dimensional flow of an Energy Efficient Engine (E3) tip section cascade for a range of incidence angles were computed in anticipation of the experimental data. The results obtained form a loss bucket for the chosen blade.

\section{SUBJECT TERMS}

Fluid mechanics and thermodynamics; Aircraft propulsion and power

\begin{tabular}{|c|c|c|c|c|c|}
\hline \multicolumn{3}{|c|}{ 16. SECURITY CLASSIFICATION OF: } & \multirow{2}{*}{$\begin{array}{l}\text { 17. LIMITATION OF } \\
\text { ABSTRACT } \\
\text { UU }\end{array}$} & \multirow{2}{*}{$\begin{array}{l}\text { 18. NUMBER } \\
\text { OF } \\
\text { PAGES } \\
26\end{array}$} & \multirow{2}{*}{$\begin{array}{l}\text { 19a. NAME OF RESPONSIBLE PERSON } \\
\text { STI Help Desk (email:help@sti.nasa.gov) } \\
\text { 19b. TELEPHONE NUMBER (include area code) } \\
\text { 443-757-5802 }\end{array}$} \\
\hline $\begin{array}{l}\text { a. REPORT } \\
U\end{array}$ & $\begin{array}{l}\text { b. ABSTRACT } \\
U\end{array}$ & $\begin{array}{l}\text { c. THIS } \\
\text { PAGE } \\
\text { U }\end{array}$ & & & \\
\hline
\end{tabular}


